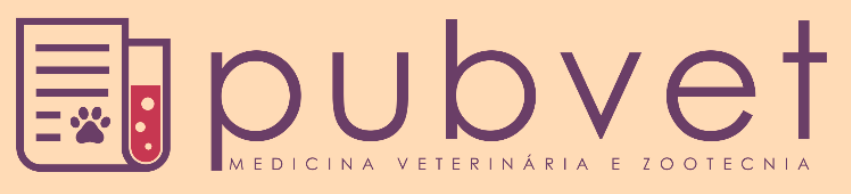

https://doi.org/10.31533/pubvet.v15n12a995.1-18

\title{
Métodos de avaliação em pastagens com ou sem animais
}

\author{
Natan Teles Cruz $^{1}{ }^{\bullet}$, Aureliano José Vieira Pires ${ }^{2} \bullet$, Braulio Maia de Lana Sousa ${ }^{3} \bullet$ (D) Renata

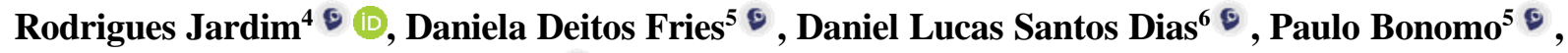 \\ Bárbara Louise Pacheco Ramos ${ }^{1 * 0}$
}

${ }^{1}$ Doutorandos em Zootecnia, Universidade Estadual do Sudoeste da Bahia (UESB), Itapetinga-BA Brasil.

${ }^{2}$ Professor, Departamento de Tecnologia Rural e Animal, UESB, Itapetinga-BA Brasil.

${ }^{3}$ Professor, Departamento de Zootecnia, Universidade Federal de Sergipe, São Cristóvão-SE Brasil.

${ }^{4}$ Bolsista PNPD, UESB, Itapetinga-BA Brasil.

${ }^{5}$ Professores, Departamento de Ciências Naturais e Exatas, UESB, Itapetinga-BA Brasil.

${ }^{6}$ Professor, Departamento de Ciências Biológicas, Universidade Estadual de Feira de Santana, Feira de Santana-BA, Brasil.

*Autor para correspondência, E-mail: agro.barbara@outlook.com

Resumo. Objetivou-se com esta revisão abordar sobre os métodos de avaliação realizados na experimentação vegetal com ou sem animais. De maneira geral, as áreas de pastagens no Brasil são as principais fontes de alimentação de ruminantes, uma vez que o país detém uma grande área territorial composta por diversas plantas forrageiras. Neste sentido, entender como os dosséis forrageiros se comportam durante determinada estratégia de manejo é de fundamental importância para elaboração do gerenciamento de pastagens. Para tanto, é necessário lançar mão de métodos de avaliações que permitem estimar uma variável desejada, servindo como base para a definição de tomadas de decisão. As técnicas de avaliação em pastagens são divididas em diretas e indiretas, onde cada método possui sua peculiaridade resultando em estimativas variáveis quando comparadas entre si. Ademais, além da escolha do método utilizado, a experimentação em pastagens deve integrar a resposta da planta à variação climática, e se possível a presença do animal no sistema. Desta maneira, é possível simular o ecossistema de pastagens dentro da experimentação e ser extrapolado para os sistemas de produção agropecuários. Assim a eficiência desses sistemas pode ser melhorada por meio dos planejamentos forrageiros desenvolvidos com base científica.

Palavras chave: Experimentação, manejo, massa de forragem, metodologia

\section{Assessment methods in pastures with or without animals}

Abstract: The objective of this review was to address the evaluation methods carried out in plant experiments with or without animals. In general, pasture areas in Brazil are the main sources of food for ruminants, since the country has a large territorial area composed of several forage plants. In this sense, understanding how forage canopies behave during a given management strategy is of fundamental importance for the development of pasture management. Therefore, it is necessary to make use of evaluation methods that allow the estimation of a desired variable, serving as a basis for the definition of decision-making. The evaluation techniques in pastures are divided into direct and indirect, where each method has its peculiarity resulting in variable estimates when compared to each other. Furthermore, in addition to the choice of method used, experimentation in pastures should integrate the plant's response to climatic variation, and if possible, the presence of the animal in the system. In this way, it is possible to simulate the pasture ecosystem within the experimentation and be extrapolated to agricultural production systems. Thus, the efficiency of these systems can be improved through forage planning developed on a scientific basis.

Keywords: Experimentation, forage mass, management, methodology 


\section{Introdução}

Um dos maiores gargalos para a atividade de ruminantes no Brasil é a utilização de pastagens que possuem determinado estágio de degradação, visto que essas áreas são compostas por plantas forrageiras, que constituem a principal forma de alimento para a produção desses animais. Para Carvalho et al. (2017) a falta de manejo adequado sob as áreas de pastagens é uma das principais causas da queda de produtividade forrageira, afetando a estabilidade socioeconômica da atividade. Neste sentido, o desenvolvimento de manejos adequados para determinada área e espécie funciona como um forte aliado para o desenvolvimento da agropecuária nacional. No entanto, para alcançar esse objetivo é necessário avaliar as plantas forrageiras levando em consideração todo o ambiente em que o sistema está envolvido, desde clima, solo, espécie forrageira e animal (Silva et al., 2015).

As elucidações sobre o potencial de determinadas espécies forrageiras são obtidas pela experimentação com o objetivo de avaliar novas técnicas de manejo que podem facilitar as tomadas de decisões dentro do sistema produtivo. Segundo Yokoyama et al. (1999), por meio da experimentação com plantas forrageiras é possível quantificar a produção, medir o fluxo de tecidos, bem como avaliar as condições estruturais do dossel forrageiro, além de quantificar suas reservas orgânicas. Com a combinação dessas avaliações, é possível obter conhecimento da resposta da planta forrageira a determinado estímulo, auxiliando na elaboração de metas racionais de pastejo. No entanto, além das características estruturais do dossel forrageiro, é necessário conhecer a disponibilidade de nutrientes das plantas para os animais presentes no sistema. Desta maneira, conhecer a qualidade nutricional de uma pastagem é um dos principais pontos para auxiliar na elaboração de dietas funcionais, e otimizar a eficiência da utilização do alimento disponível.

As respostas dos animais em pastagens sob diferentes manejos é uma maneira de complementar os dados morfológicos ajudando a encontrar o equilíbrio entre a produção e persistência da pastagem e o desempenho animal. Assim, a presença do animal em experimentos com pastagem é um fator necessário, visto que o principal objetivo da produção de pastagens é servir como fonte de alimento para a produtividade animal (Bonnet et al., 2015).

No entanto, a presença do animal no sistema experimental depende do objetivo principal do estudo, uma vez que, quando o objetivo central do trabalho é a avaliação da forragem, é possível que seja realizada avaliações que simulam o processo de desfolhação. Adicionalmente, alguns experimentos utilizam o animal apenas como agente desfolhador, obtendo um pastejo real para a avaliação do dossel forrageiro. Assim, as características produtivas dos animais não são avaliadas, e apenas o dossel forrageiro é estudado.

O padrão de crescimento das plantas forrageiras é fortemente influenciado pelo ambiente pelo manejo aplicado à área formada por pastagem, resultando no processo de adaptação da planta a determinado manejo (Pimentel et al., 2016). Neste sentido, para a avaliação de plantas forrageiras existe um conjunto de técnicas divididas entre métodos diretos, indiretos, onde a escolha da técnica a ser utilizada irá depender do objetivo do trabalho e da disponibilidade de insumos.

De maneira geral, a utilização dos métodos diretos é bem difundida para avaliação de plantas forrageiras, e baseia-se no corte da pastagem em áreas de tamanho conhecido, apresentando-se como um método destrutivo, pois há necessidade do corte da forrageira para estimar sua produtividade (Suyama et al., 2007).

Hodgson (1981) já alertava que, apesar de ser uma fonte de dados confiáveis, o método de avaliação direta poderia cair em desuso, por conta da necessidade de corte e quantidade da amostragem em determinada área. Neste sentido, com a evolução tecnológica está sendo possível aplicar técnicas de avaliações indiretas, com precisão e necessidade de menor mão de obra. Por exemplo, a estimativa de produção de forragem através do sensoriamento remoto é promissora para estudos de grandes áreas de pastagens (Morais et al., 2018).

Objetivou-se com esta revisão abordar a importância da utilização dos métodos de avaliação de pastagens na elaboração de metas sustentáveis de atividades agropecuárias. 


\section{Tipos de avaliações quantitativas em plantas forrageiras e seus métodos}

De maneira geral a avaliação quantitativa baseia-se em estimar a capacidade de produção de massa seca de uma planta forrageira. Segundo Silva et al. (2018) a avaliação da disponibilidade de forragem é de fundamental importância para o planejamento estratégico de pastagens, visto que as respostas científicas servirão de base para extrapolar os resultados para o sistema produtivo. Existem várias maneiras de quantificar a disponibilidade ou produção de uma área de pastagem. Os métodos de avaliação são subdivididos entre direto, onde exige o corte da forragem amostrada, e indireto, que possibilita estimar a produção de uma planta forrageira sem necessidade de corte (Morais et al., 2018). Ambos os métodos possuem prós e contras, e a escolha entre qual método será utilizado na avaliação irá depender dos objetivos, mão de obra necessária para realização da atividade e dos recursos financeiros disponíveis. Além disso, a quantidade de amostras necessárias para a quantificação da massa seca deve ser levada em conta, uma vez que dosséis forrageiros geralmente não possuem crescimento uniforme, necessitando de maior quantidade de amostras para reduzir o erro experimental. Neste sentido, experimentos realizados em grandes áreas de forragem necessitam de maiores quantidades de amostragem quando comparados a experimentos conduzidos em parcelas menores.

De maneira geral o método de avaliação escolhido deve representar de forma precisa à área estudada para que não haja sub ou superestimação das condições do dossel forrageiro, podendo induzir erros ao sugerir novas estratégias de gestão (Zanine et al., 2006). No entanto, existe uma variação entre a diversidade de espécies forrageiras e suas respostas morfológicas frente a um fator estresse e ambiente local. Assim é necessário que todo ecossistema seja levado em conta durante as avaliações com pastagens para que os fatores envolvidos possam ser estudados auxiliando no entendimento do acúmulo de forragem.

\section{Método direto}

É o método mais utilizado para quantificar a produção de plantas forrageiras em condições experimentais, apresentando elevada precisão e confiabilidade. No entanto, utilizar este método exige maior necessidade de mão de obra, de acordo com o tamanho da área a ser avaliada e quantidade de amostras necessárias, podendo levar maior tempo para descrever a estimativa produtiva de uma área. Segundo Zanine et al. (2006) este método baseia-se na remoção da forragem contida dentro de uma área conhecida, sendo assim considerado um método destrutivo de avaliação. De maneira geral, é utilizado uma moldura em forma quadrada ou retangular de área conhecida, além dos equipamentos necessários para o corte e pesagem da forrageira, como balança portátil, e um equipamento cortante.

O tamanho e forma do quadro amostral depende da uniformidade da área e dos hábitos de crescimento da gramínea amostrada (Edvan et al., 2016). Neste sentido, Salman et al. (2006) relatam que as áreas do quadro podem variar entre 0,1 a $2 \mathrm{~m}^{2}$, onde quadros menores são utilizados em áreas uniformes, e quadro maiores, em áreas que apresentam maiores heterogeneidades. Além disso, o tamanho e formato do quadro amostral pode variar de acordo com o hábito de crescimento da planta amostrada (Tabela 1).

Tabela 1. Formas e medidas de quadros amostrais para avaliação da massa de forragem.

\begin{tabular}{llll}
\hline Forragem & Hábito de crescimento & Dimensões $(\mathrm{m})$ & Área $^{\left(\mathrm{m}^{2}\right)}$ \\
\hline Cynodon spp. & Prostrado, rasteiro & $0,5 \times 0,5$ ou 0,5 x 1,0 & 0,25 ou 0,5 \\
Digitaria, Brachiaria & Prostado, subprostrado, decumbente & $1,0 \times 1,0$ ou 0,5 x 2,0 & 1,0 \\
Panicum, Pennisetum, Andropogon & Ereto, formação de touceiras & $1,5 \times 1,5$ ou 1 x 2,25 & 2,25 \\
\hline
\end{tabular}

Fonte: Adaptado de Salman et al. (2006).

Para que o método de avaliação direta seja mais preciso e confiável, é necessário que tenha um mínimo de amostras que representam a área total. Neste sentido, o número de amostras necessárias para a obtenção de uma estimativa confiável deve ser suficiente para representar a variações existente no dossel forrageiro. Adicionalmente, Huuskonen et al. (2013) afirmaram que para obter uma amostragem confiável é necessário que todos os componentes estruturais e sua variabilidade dentro do dossel forrageiro devem estar representados na amostra. A seguir é demonstrado as etapas para estimar a massa de forragem por meio do método direto: 
- Etapa 1: Reconhecimento da área a ser avaliada, que pode ser feito pelo caminhamento em "W" ou em linhas transversais (Figura 2). Assim será possível determinar as dimensões e ter uma ideia acerca da heterogeneidade da área a ser amostrada.
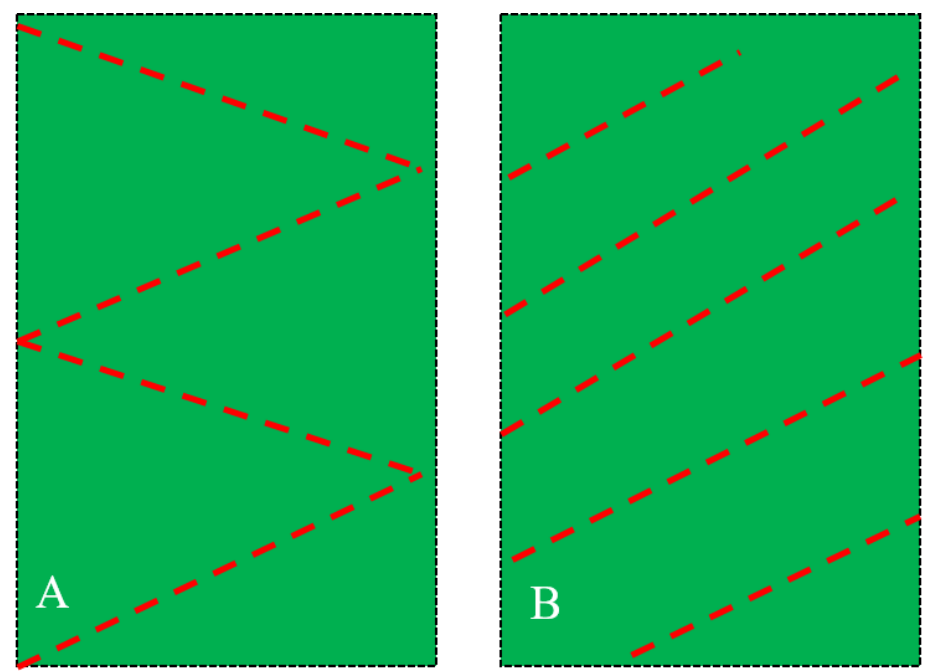

Figura 1. Formas de caminhamento para reconhecimento da área a ser amostrada. O caminhamento pode ser feito em $\mathrm{W}$ (A) ou em linhas transversais (B)

- Etapa 2: Definir qual a estratégia para a coleta da amostra necessária para a estimativa da forragem. De acordo com Huuskonen et al. (2013) as coordenadas de coleta podem ser definidas de maneira aleatória quando o dossel forrageiro apresenta pouca heterogeneidade da massa de forragem. No entanto, quando a heterogeneidade é alta, o autor recomenda a escolha de estações que representariam a massa de forragem do dossel. Neste caso, o uso do bom senso e experiência do pesquisador são necessários para que não haja super ou subestimação da massa de forragem da área (Salman et al., 2006). Em casos em que a área experimental é limitada, a área colhida para amostragem pode compreender $50 \%$ ou mais da área total da parcela, sendo necessário fazer menos amostragem para estimativa da massa de forragem. Na Figura 3 é demonstrado um exemplo de coleta amostral em áreas de forragens.
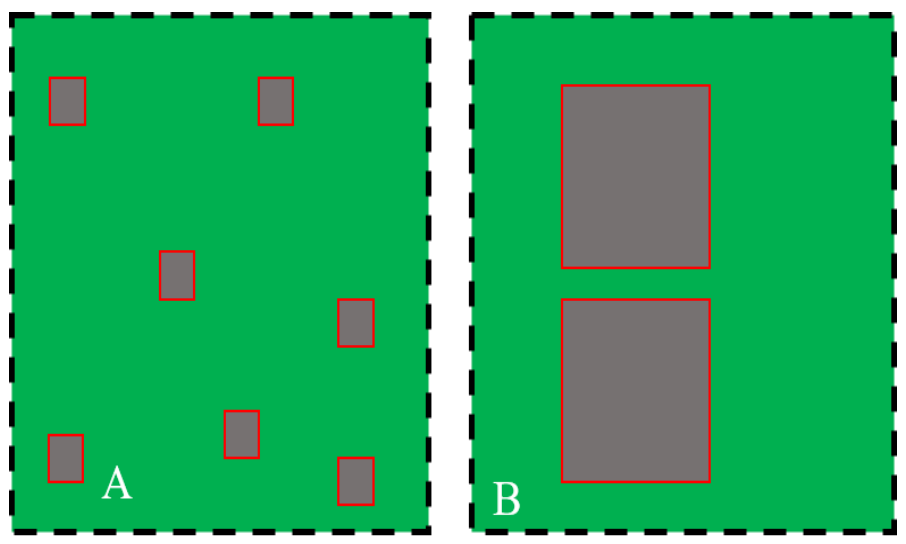

Figura 2. Representação da coleta de amostragem em áreas de forragem. A: Exemplo de amostragem em piquetes medindo $20 \times 20 \mathrm{~m}\left(400 \mathrm{~m}^{2}\right)$, e o quadro amostral de $1 \mathrm{x} 1 \mathrm{~m}\left(1 \mathrm{~m}^{2}\right)$. Em grandes áreas experimentais é necessário que seja feita uma quantidade maior de coletas para reduzir a variabilidade na estimativa dos dados de massa de forragem. Assim, requer maior necessidade de mão de obra e equipamentos, aumentando consequentemente seus custos. B: Amostragem em parcelas medindo $3 \times 3 \mathrm{~m}\left(9 \mathrm{~m}^{2}\right)$, com quadro amostral medindo $1 \times 1 \mathrm{~m}$ (1 $\mathrm{m}^{2}$ ). Menores quantidades de amostras são necessárias quando o experimento é conduzido em áreas limitadas. É necessário coletar o material que mais representa as condições da parcela, excluindo-se sua bordadura, e reservando uma área para outras coletas com a planta forrageira. Adicionalmente, o corte, rente ao solo, das plantas não é recomendado, visto que altera a estrutura do local amostrado, podendo interferir nas coletas posteriores na mesma parcela. 
- Etapa 3: Após definir os locais de coleta, é realizado um corte das amostras presentes dentro do quadro amostral. Cada amostra deve ser colocada em sacos plásticos e levadas ao laboratório. Neste momento é determinado o peso fresco total de cada amostra utilizando uma balança. Após esse procedimento é retirada uma sub amostra de cada amostra, onde será acondicionada em sacos de papeis, pesadas (para a obtenção do peso fresco da sub amostra) e colocadas em estufas de ventilação forçada de ar, durante $72 \mathrm{~h}$ a $55^{\circ} \mathrm{C}$. Os equipamentos utilizados nessa etapa estão demonstrados na Figura 4.

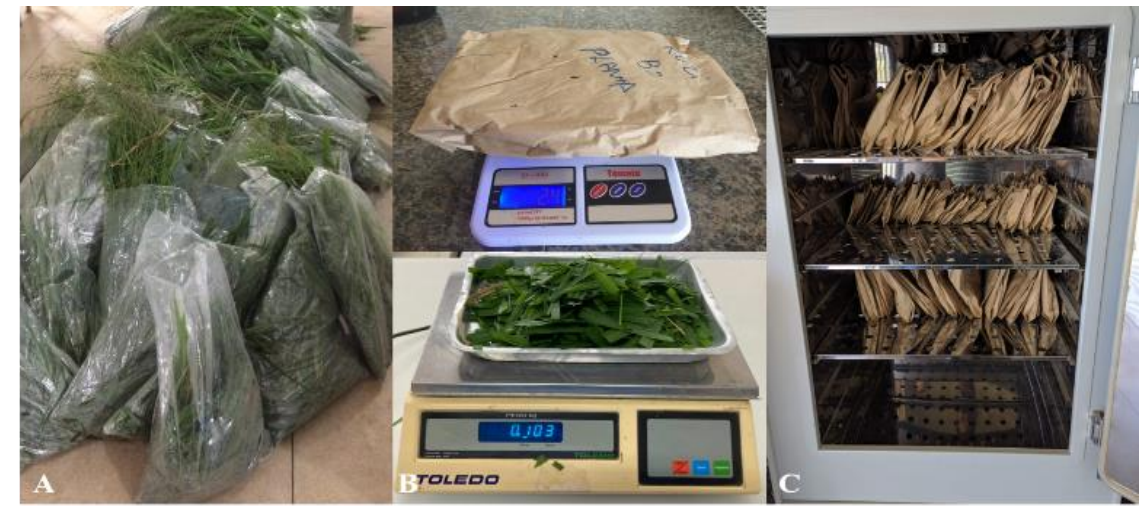

Figura 3. A: Sacos plásticos onde são colocadas cada amostra coletada no interior do quadro amostral. B: Balança utilizada para pesar a massa dos materiais colhidos, além da subamostra retirada de cada coleta. C: Sacos de papeis contendo a subamostra retirada e colocada para secar em estufa de ventilação forçada.

Neste momento é possível estimar o teor de matéria seca da forrageira avaliada. No entanto, a descrição do cálculo a seguir apresenta apenas uma estimativa desse teor, sendo necessário utilizar um método específico para estimativa do teor de matéria seca real de uma amostra (Silva \& Queiroz, 2002). Neste sentido, para estimar o teor de matéria seca de uma amostra ao final desta etapa procede-se com o seguinte cálculo:

Teor de matéria seca $(\%)=($ Peso seco amostra $/$ Peso fresco amostra $) * 100$.

- Etapa 4- 4: Após $72 \mathrm{~h}$ os sacos de papel com as subamostras são retirados da estufa, e quando os mesmos atingem a temperatura ambiente, o material é novamente pesado, desta vez seco. Assim, é possível estimar a massa de forragem contida no quadro amostral a partir de uma regra de três básica:

$$
\begin{aligned}
& \text { Massa fresca sub amostra ------------- Massa seca sub amostra } \\
& \text { Massa fresca quadro amostral -------- X }=\text { Massa seca quadro amostral }
\end{aligned}
$$

Com os dados da massa de forragem contida no quadro amostral, é possível extrapolar os resultados para áreas maiores, obtendo-se a produção da massa de forragem (MF) da planta forrageira por hectare (Sbrissia et al., 2018). Assim, o cálculo baseia-se da seguinte maneira:

$$
\text { MF }(\text { kg.ha-1 })=(\text { Massa seca quadro amostral em kg * 10.000) / Área do quadro }
$$

$\mathrm{Na}$ Tabela 2, segue um exemplo no qual deseja-se saber a produção por hectare de uma determinada planta forrageira, utilizando uma área de $900 \mathrm{~m}^{2}$. Neste exemplo foi utilizado dados de seis coletas em locais aleatórios, considerando um dossel uniforme utilizando um quadro amostral de $0,7 \mathrm{~m}^{2}$.

Tabela 2. Exemplo de estimativa do teor de matéria seca e massa de forragem em uma área experimental.

\begin{tabular}{lcccc}
\hline Ponto amostral aleatório & PF Quadro (g) & PS Quadro (g) & MS (\%) & MF $\left(\mathrm{kg.ha}^{-1}\right)$ \\
\hline 1 & 842 & 115 & 13,7 & 1.646 \\
2 & 510 & 90 & 17,6 & 1.280 \\
3 & 614 & 93 & 15,1 & 1.324 \\
4 & 825 & 167 & 20,3 & 2.392 \\
5 & 865 & 124 & 14,4 & 1.776 \\
6 & 915 & 108 & 11,8 & 1.543 \\
\hline Média & 762 & 116 & 15,5 & 1.660 \\
\hline
\end{tabular}




\section{PF: Peso fresco; PS: Peso seco; MS: Matéria seca; MF: Massa de forragem.}

De modo geral, para determinar a produção de massa de forragem total a altura de corte da amostragem é feita ao nível do solo, com o objetivo de minimizar os erros, uma vez que o estabelece o nível do solo como referencial comum (Maciel et al., 2014). No entanto, o corte rente ao solo proporciona mudanças na estrutura do dossel forrageiro prejudicando a rebrota naquele ponto de amostragem. Assim é recomendado que o corte rente ao solo para a estimativa da massa de forragem seja feito em sítios experimentais que não possuem limitação em área, podendo ser feita várias amostragens durante o período necessário para experimentação.

Após a quantificação da massa de forragem (MF), é possível quantificar o quanto determinada planta acumulou de massa durante o período experimental. Segundo Pedreira (2002), em experimentos em lotação intermitente a estimativa do acúmulo de massa de forragem (AF) pode ser obtida através da fórmula:

$$
\text { AF = MF pré pastejo ciclo } n-\text { MF pós pastejo ciclo n-1 }
$$

Adicionalmente, quando existe limitação de área experimental não é recomendada a utilização do corte rente ao solo para a estimativa de massa total. Assim é possível calcular o acúmulo de massa através de cortes na altura de resíduo preconizada, preservando a área experimental. Silva et al. (2019) trabalhando em piquetes com área média de $2000 \mathrm{~m}^{2}$, avaliaram a estimativa de massa de forragem do capim Marandu pelo corte rente ao solo, e o acúmulo através da diferença da massa pré e pós pastejo do animal. Já Fontes et al. (2020) avaliaram o capim survenola (Digitaria eriantha cv. Survenola) em parcelas com tamanho médio de $9 \mathrm{~m}^{2}$ e obtiveram estimativas da taxa de acúmulo de massa e dos componentes morfológicos, apesar da impossibilidade de estimar a massa total, devido ao tamanho reduzido da área experimental.

O uso de animais em experimento com plantas forrageiras é interessante do ponto de vista ambiental, visto que o animal faz parte do sistema produtivo e sua presença na área experimental exibe a condição real de pastejo. No entanto, limitações financeiras ou de área são fatores que podem impossibilitar a utilização de animais em experimento com pastagens. Assim, a utilização de cortes é uma forma de avaliar a pastagem quando o objetivo for de simular um pastejo rotativo, sem a necessidade da presença do animal em pastejo.

De modo geral, quando a avaliação se refere ao sistema de taxa de lotação contínua é comum a utilização de animais durante o experimento, devido à natureza do manejo. Na maioria das vezes, o objetivo central dos experimentos em lotação contínua é de avaliar a forragem pastejada continuamente, assim é indispensável o uso de animais neste sistema de experimentação. Neste sentido, é necessário o uso de gaiolas de exclusão, que como o nome sugere, é utilizada com o objetivo de proteger uma área do pastejo animal. Adicionalmente, Zanine et al. (2006) alertam que o tamanho interno da gaiola não seja menor que $1 \mathrm{~m}^{2}$ para evitar mudanças no microclima desta área amostrada e interferir na avaliação do dossel. Além disso, Hodgson (1990) ressaltou que existe limitações no uso das gaiolas de exclusão, tais como o fato de não haver influência da distribuição da urina e fezes, bem como a falta do efeito de pisoteio pelos animais, dentro da área "excluída".

Para a obtenção do acúmulo de forragem em experimentos sob lotação contínua, onde não há ciclos de pastejo, e sim ciclos de amostragem, Zanine et al. (2006) sugerem que é necessário realizar o corte de uma área amostral em um local semelhante à área que irá receber a gaiola. Assim, ainda segundo os autores, quando a produção de forragem no interior da gaiola for quantificada, o acúmulo de massa é estimado através da diferença de produções das duas áreas.

Levando em consideração que o ciclo de amostragem seja de 15 dias, é necessário realizar um corte amostral fora das gaiolas no dia "zero". Após passados os 15 dias de ciclo de amostragem, estima-se a massa de forragem dentro das gaiolas de exclusão, e fora em áreas aleatórias do dossel pastejado (Gomes et al., 2014). Neste sentido, é possível estimar o acúmulo de forragem pela fórmula descrita por Pereira et al. (2014):

\section{AF $=$ MF gaiolas dia $15-$ MF pastagem dia zero}

Ainda segundo o autor, para a próxima avaliação do ciclo de amostragem é necessário rotacionar os locais das gaiolas, e a massa de forragem do pasto é novamente quantificada (MF da pastagem no dia 15 ), assim após mais 15 dias pode se calcular o acúmulo de forragem através da fórmula: 


\section{$\mathrm{AF}=\mathrm{MF}$ gaiolas dia $30-\mathrm{MF}_{\text {pastagem dia } 15}$}

Desta maneira, em cada ciclo de amostragem é preciso medir a massa de forragem inicial para o próximo ciclo de amostragem, e massa de forragem ao final do ciclo de amostragem que chegou ao final (Pereira et al., 2014). Adicionalmente, é desejável que os ciclos de amostragem sejam os mais curtos possíveis, para que não haja um grande acúmulo de forragem dentro da gaiola modificando o microclima daquele local específico ocasionando mudanças na estrutura da forragem, fugindo da condição real do dossel forrageiro.

\section{Métodos indiretos}

Devido à necessidade de amostragem em áreas extensas de pastagens, e a sua heterogeneidade, é necessário grande uso de mão de obra para a utilização do método de avaliação direta. Por outro lado, em pequenas áreas experimentais existe a limitação da quantificação da massa total de forragem, pois cortes rente ao solo poderá comprometer a estrutura do dossel dentro de toda parcela experimental. Assim, métodos de avaliação indiretos foram desenvolvidos com o intuito de obter uma estimativa da produção de massa de uma forragem com caráter não destrutivo (Pellegrini et al., 2010). Além disso, a utilização dos métodos indiretos para a estimativa da massa de forragem aparece com o objetivo de viabilizar uma rápida avaliação, com menor necessidade de mão de obra e potencialmente menos onerosa, comparados aos métodos diretos (Gomes et al., 2014).

Na utilização do método de avaliação indireto é necessário que seja feita incialmente uma amostragem de forma direta, para que possa ser correlacionado com o método indireto que será utilizado (Edvan et al., 2016). Desta maneira é possível obter curvas de calibração, através de equações de regressão, abrangendo o ecossistema da área avaliada e o maior número de características que se correlacionam com a massa de forragem (Zanine et al., 2006). Assim, segundo Pedreira (2002) após a estimativa das curvas de calibração torna-se possível realizar um grande número de amostragem na área estudada, integrando a variabilidade do ecossistema de pastagens, sendo possível realizar um maior número de amostragens na área estudada. Ademais, ainda segundo o autor, é necessário que seja o maior número de amostragem possível para uma melhor calibração das curvas de predição, reduzindo o erro das estimativas indiretas. Dentre os métodos de avalição indiretos podemos destacar:
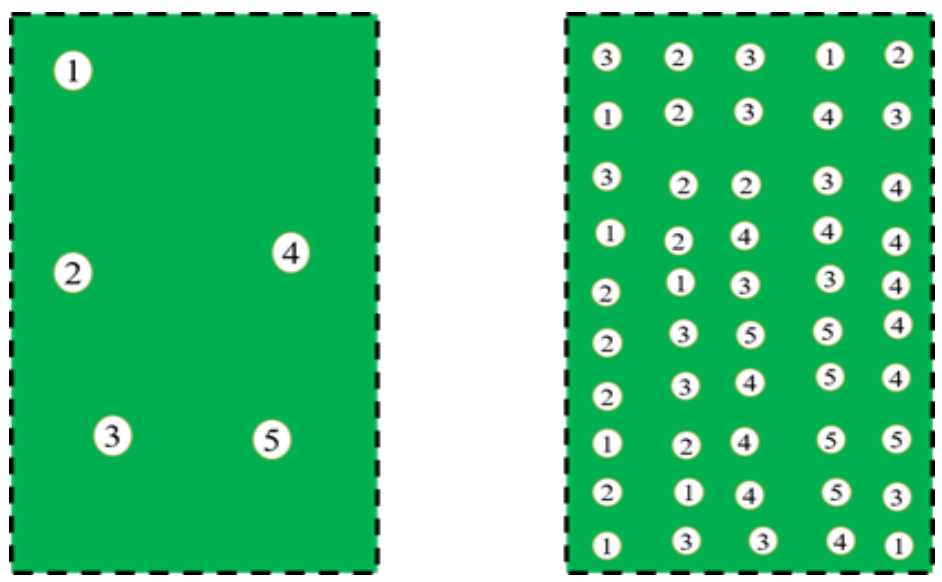

Figura 4. Esquematização do uso do método de rendimento visual comparativo. Primeiramente é definido um padrão para cada escore, que pode variar de 1 a 5. Após a atribuição de notas a esses locais, uma amostra representativa de cada escore é cortada para estimar sua massa de forragem, através do método direto. A partir daí é feita uma calibração através de equações de regressão para ajustar a relação entre o escore e a massa de forragem. Após a definição da equação, esta pode ser utilizada para dosséis da mesma espécie e mesmo estádio de maturidade em que a mesma foi criada. Desta maneira, é possível realizar um maior número de estimativa visual da área avaliada, onde a média dos escores serve para estimar a massa de forragem naquele local. Fonte: Gomes et al. (2014).

- Rendimentóvisual comparatativo: permite estimar a produção de massa de forragem através de escores de 1 a 5 , determinado visualmente, para as condições do pasto em pontos diferentes do dossel forrageiro. 
Pedreira (2002) descreve que após a atribuição das notas, é feito o corte da área avaliada para que haja calibração da equação correspondente ao escore e à massa de forragem (igura 6).

Na Tabela 3 segue um exemplo da aplicação prática deste método, onde os escores foram atribuídos à cada local, e após a definição da equação de regressão, foram estimados 50 pontos, com média de escore 2,7. Para a coleta das amostras foi utilizado como exemplo um quadro amostral de $0,7 \mathrm{~m}^{2}$.

Tabela 3. Exemplo de estimativa de massa de forragem MF através do método de rendimento visual comparativo.

\begin{tabular}{|c|c|c|c|c|}
\hline Escore & PF Quadro (g) & PS Quadro (g) & MS (\%) & MF (kg.ha ${ }^{-1}$ de MS) \\
\hline$\overline{1}$ & 149 & 26 & 17 & 365 \\
\hline 2 & 178 & 31 & 17 & 437 \\
\hline 3 & 304 & 58 & 19 & 827 \\
\hline 4 & 454 & 69 & 15 & 985 \\
\hline 5 & 500 & 77 & 15 & 1105 \\
\hline \multirow{2}{*}{ Equação de Regressão } & \multirow{2}{*}{\multicolumn{3}{|c|}{ MF $=135,4+202,8 *$ Escore médio }} & $\mathrm{R}^{2}(\%)$ \\
\hline & & & & 94,9 \\
\hline
\end{tabular}

PF: Peso fresco; PS: Peso seco; MS: Matéria Seca; MF: Massa de Forragem; R²: Coeficiente de determinação.

Cóser et al. (2003) avaliaram a estimativa da produção de massa seca do capim elefante, obtida através da técnica de rendimento visual comparativo, por quatro observadores diferentes. Os autores relatam esta técnica é eficiente para estimar a produção de forragem do capim elefante, visto que os valores dos coeficientes de determinação $\left(\mathrm{R}^{2}\right)$ foram acima de $80 \%$, sendo o mínimo preconizado para aceitação do método de estimativa de forma indireta (Tabela 4). Além disso, os autores relataram que não houve diferença significativa entre os avaliadores, demonstrando a possibilidade de estimar a produtividade da forragem de maneira semelhante.

Tabela 4. Equações de regressão da produção de matéria seca de capim elefantes obtidos através do método de rendimento visual comparativo por quatro observadores diferentes.

\begin{tabular}{lccc}
\hline Observador & Equação de regressão & $\mathrm{R}^{2}(\%)$ & $\mathrm{CV}(\%)$ \\
\hline 1 & $\hat{\mathrm{Y}}=256,85+763,5 \mathrm{x}$ & 96 & 6,0 \\
2 & $\hat{\mathrm{Y}}=109,94+820,69 \mathrm{x}$ & 95 & 7,4 \\
3 & $\hat{\mathrm{Y}}=92,97+819,17 \mathrm{x}$ & 92 & 9,2 \\
4 & $\hat{\mathrm{Y}}=138,16+815,81 \mathrm{x}$ & 94 & 8,4 \\
\hline
\end{tabular}

$\mathrm{R}^{2}$ : Coeficiente de determinação; CV: Coeficiente de variação. Adaptado de Cóser et al. (2003).

Lima et al. (2015) avaliaram a técnica de estimativa direta (corte) e a de rendimento visual comparativo para estimar a fração de cobertura do solo formado por Brachiaria ruziziensis semeado em três diferentes métodos: semeadura a lanço, a lanço com incorporação ao solo, e semeadura em linha. Os autores relataram que independentemente do método de semeadura, as técnicas de estimativa de fração de cobertura são semelhantes quando avaliados 90 dias após a semeadura (Tabela 5).

Tabela 5. Percentagem de cobertura do solo obtida pelos diferentes métodos em dosséis de Brachiaria ruziziensis semeados de diferentes formas.

\begin{tabular}{lcc}
\hline \multirow{2}{*}{ Método de semeadura } & \multicolumn{2}{c}{ Método de avaliação } \\
\cline { 2 - 3 } & Corte & Rendimento visual \\
\hline Lanço & $99,25 \mathrm{a}$ & $100 \mathrm{a}$ \\
Lanço com incorporação & $99,88 \mathrm{a}$ & $100 \mathrm{a}$ \\
Linha & $100 \mathrm{a}$ & $100 \mathrm{a}$ \\
\hline
\end{tabular}

Médias seguidas por mesma letra minúscula na linha não diferem entre si pelo teste de Tukey ( $\mathrm{P}>0,05)$. Adaptado de Lima et al. (2015).

No entanto a utilização da técnica de rendimento visual comparativo pode resultar em elevada variabilidade nos resultados exigindo treinamento do observador para que não haja super ou subestimação da produção de forragem (Maciel et al., 2014). Assim, este método apresenta restrições para sua utilização na pesquisa, no entanto pode ser utilizada para aplicações práticas no gerenciamento de pastagens. 
- Altura do horizonte (não comprimida) do dossel: permite estimar a produção de massa de forragem através da medição da altura $(\mathrm{cm})$ do dossel forrageiro. Segundo Deminicis (2015) utiliza-se uma régua graduada em centímetros para a obtenção da altura do dossel e posterior calibração para estimar a massa de forragem da área. Os pontos de coleta da altura podem ser coletados da mesma forma do reconhecimento da área (Figura 2), sendo a altura do dossel, correspondente à média dos pontos coletados. Zanine et al. (2006) descreveram que a medida da altura do pasto deve ser realizada do solo até a curvatura média no ponto mais alto do dossel forrageiro. Ainda segundo os autores, existe uma adaptação desse método, que, além da régua, consiste no uso de uma folha de transparência, colocada sob a vegetação, fornecendo um valor médio das alturas que a folha de transparência toca na régua.

Assim este método apresenta-se como alternativa pouco onerosa, devido o requerimento de uma régua graduada e treinamento do observador. Apesar disto, mesmo em condições de homogeneidade da pastagem, existe mudanças na densidade volumétrica entre os estratos do dossel forrageiro, resultando em baixa exatidão na estimativa da massa de forragem (Moterle et al., 2017; Pedreira, 2002). Ademais, segundo Edvan et al. (2016) a utilização deste método não fornece estimativas confiáveis acerca da produção de forragem, visto que os autores relataram que os coeficientes de determinação $\left(\mathrm{R}^{2}\right)$ das equações obtidas através da altura, descritas na literatura científica, variam entre 40 e $93 \%$.

Em contrapartida, a medição da altura do dossel auxilia na definição de estratégias de pastejo, uma vez que existe uma forte correlação entre a altura do pasto e o momento de entrada dos animais (condição pré pastejo) (Martins et al., 2020).

- Altura comprimida do dossel: baseia-se na utilização de um disco ou prato que se movimenta através de uma coluna graduada em centímetros, assim, a realização da medida é feita com a compressão da forragem (Silva et al., 2016). Além do referencial de altura, a utilização deste método possui a capacidade de integrar a densidade da forragem na área. Assim, ao combinar a densidade de forragem com sua altura, é possível estimar a massa de forragem da área com maior exatidão (Gomes et al., 2014). Apesar de ser um método simples e objetivo, Pedreira (2002) alertou que esta técnica pode apresentar limitações quando utilizados em vegetações altas com colmos rígidos, assim a medida pode não levar em conta a densidade da vegetação. Neste caso, o autor explica que, devido à falta de compressão, se leva em consideração apenas a altura, resultando em fracas correlações entre a altura comprimida e a massa de forragem do dossel, demonstrando redução na sua eficiência em dosséis com maiores alturas. Assim, Edvan et al. (2016) e Edvan et al. (2013) sugeriram que a utilização da técnica da altura comprimida seja feita em áreas formadas por pastagens que não possuam crescimento cespitoso com grande formação de colmos rígidos. Silva \& Cunha (2003) avaliaram os métodos de altura comprimida e não comprimida do dossel forrageiro para estimar a massa de forragem em pastos de Cynodon spp. durante o verão e inverno. Os autores concluíram que a calibração dos métodos deve ser feita separadamente para cada espécie e periodicamente, visto que existe variação na estrutura do dossel em função da variação das estações do ano (Tabela 6).

Tabela 6. Equações de calibração para estimativa da massa de forragem (kg.ha-1 de MS) em pastos formados por Cynodon spp.

\begin{tabular}{|c|c|c|c|c|}
\hline \multirow[t]{2}{*}{ Cultivar } & \multicolumn{4}{|c|}{$\begin{array}{c}\text { Verão } \\
\text { Método de avaliação }\end{array}$} \\
\hline & Disco Medidor & $\mathrm{R}^{2}(\%)$ & Altura não comprimida & $\mathrm{R}^{2}(\%)$ \\
\hline Florarkik & $\hat{\mathrm{Y}}=1660+145^{*} \mathrm{AC}$ & 80 & $\hat{\mathrm{Y}}=1260+220 * \mathrm{AL}$ & 77 \\
\hline Tifton 85 & $\hat{\mathrm{Y}}=1515+160 * \mathrm{AC}$ & 77 & $\hat{\mathrm{Y}}=895+265^{*} \mathrm{AL}$ & 81 \\
\hline \multirow[t]{3}{*}{ Coastcross } & $\hat{\mathrm{Y}}=995+155^{*} \mathrm{AC}$ & 86 & $\hat{\mathrm{Y}}=710+215^{*} \mathrm{AL}$ & 85 \\
\hline & \multicolumn{4}{|c|}{$\begin{array}{c}\text { Inverno } \\
\text { Método de avaliação }\end{array}$} \\
\hline & Disco Medidor & $\mathrm{R}^{2}(\%)$ & Altura não comprimida & $\mathrm{R}^{2}(\%)$ \\
\hline Florarkik & $\hat{\mathrm{Y}}=2790+115^{*} \mathrm{AC}$ & 68 & $\hat{\mathrm{Y}}=2720+155^{*} \mathrm{AL}$ & 61 \\
\hline Tifton 85 & $\hat{\mathrm{Y}}=2855+145 * \mathrm{AC}$ & 73 & $\hat{\mathrm{Y}}=2470+230 * \mathrm{AL}$ & 69 \\
\hline Coastcross & $\hat{\mathrm{Y}}=1965+135 * \mathrm{AC}$ & 68 & $\hat{\mathrm{Y}}=1755+170 * \mathrm{AL}$ & 64 \\
\hline
\end{tabular}

$\mathrm{R}^{2}$ : Coeficiente de determinação; AC: Altura comprimida do dossel em unidades de leitura do disco; AL: Altura do dossel em centímetros. Adaptado de Silva \& Cunha (2003). 
Além disso, Silva \& Cunha (2003) relataram que os dois métodos avaliados não diferem em eficácia na estimativa de massa de forragem desde que as curvas sejam geradas através de um conjunto de dados que represente a variabilidade do dossel forrageiro. No entanto, Paciullo et al. (2004) avaliaram a estimativa de forragem em pastos formados por capim coastcross (Cynodon dactylon) e capim estrela (Cynodon nlemfuensis) pela técnica do disco comprimido e da altura dossel em experimento conduzido em Coronel Pacheco, MG. Os autores relataram que a técnica do disco comprimido obteve maior confiabilidade em comparação à altura não comprimida, visto que resultou em maior coeficiente de determinação $\left(\mathrm{R}^{2}\right)$ da equação de regressão (Tabela 7).

Tabela 7. Equações de regressão para estimativa da massa de forragem (kg.ha ${ }^{-1}$ de MS) através da altura comprimida e da altura não comprimida do dossel em pastos formados por Cynodon spp.

\begin{tabular}{llc}
\hline Método de Avaliação & Equação de Regressão & $\mathrm{R}^{2}(\%)$ \\
\hline Disco Medidor & $\hat{\mathrm{Y}}=-67,3+174,6^{*} \mathrm{AC}$ & 75 \\
Altura não comprimida & $\hat{\mathrm{Y}}=-876,1+143,4 * \mathrm{AL}$ & 58 \\
\hline
\end{tabular}

$\mathrm{R}^{2}$ : Coeficiente de determinação; AC: Altura comprimida do dossel em unidades de leitura do disco; AL: Altura do dossel em centímetros. Adaptado de Paciullo et al. (2004).

Desta maneira, para escolha do método utilizado deve se levar em consideração a espécie forrageira, época do ano e estado de maturidade da planta. Neste sentido, na Tabela 8 é demonstrado uma compilação de resultados referentes às técnicas de altura não comprimida e comprimida do dossel forrageiro para a estimativa da massa de forragem disponível.

Tabela 8. Estimativas de massa de forragem através de equações de regressão de diferentes espécies forrageiras obtidas através dos métodos de altura comprimida (disco medidor) e não comprimida (régua) do dossel.

\begin{tabular}{|c|c|c|c|c|c|}
\hline Espécie & Método & Equação & $\mathrm{R}^{2}(\%)$ & Unidade & Autor \\
\hline \multirow{2}{*}{ Brachiaria brizantha } & Régua & $\hat{\mathrm{Y}}=507,4+105,1 * \mathrm{AL}$ & 93 & \multirow{2}{*}{ kg.ha-1 de MS } & \multirow{2}{*}{ Braga et al. (2009) } \\
\hline & Disco & $\hat{\mathrm{Y}}=2768,6+56,2 * \mathrm{AD}$ & 95 & & \\
\hline Brachiaria decumbens & Disco & $\hat{\mathrm{Y}}=16,4+2,4 * \mathrm{AD}$ & 92 & kg.ha-1 de MS & Gomide et al. (2001) \\
\hline \multirow{2}{*}{ Cynodon nlemfuensis } & Régua & $\hat{\mathrm{Y}}=987+192 * \mathrm{AL}$ & 56 & \multirow{2}{*}{ kg.ha-1 de MS } & \multirow{2}{*}{ Arruda et al. (2011) } \\
\hline & Disco & $\hat{\mathrm{Y}}=1227+171 * \mathrm{AD}$ & 64 & & \\
\hline \multirow{2}{*}{ Axonopus catharinensis } & Régua & $\hat{\mathrm{Y}}=108,5+735.5^{*} \mathrm{AL}$ & 57 & \multirow{2}{*}{ kg.ha-1 de MS } & \multirow{2}{*}{ Dufloth et al. (2015) } \\
\hline & Disco & $\hat{\mathrm{Y}}=87+231 * \mathrm{AD}$ & 73 & & \\
\hline Pastagem nativa & Disco & $\hat{\mathrm{Y}}=31,11+3,27 * \mathrm{AD}$ & 90 & kg.m $\mathrm{m}^{-2}$ de MS & Pellegrini et al. (2010) \\
\hline
\end{tabular}

Altura do disco comprimido; AL: Altura do dossel forrageiro $\mathrm{R}^{2}$ : Coeficiente de determinação expresso em porcentagem.

- Sonda eletrônica: de acordo com Carvalho (2008) a aferição desta variável é feita a partir da capacidade elétrica da forragem, visto que a capacitância do ar é menor que a capacitância do dossel forrageiro. Adicionalmente, esta técnica é realizada através de uma sonda que determina a capacitância elétrica existente na forragem. No entanto, Deminicis (2015) enfatizou que é necessário realizar um grande número de calibração pois deve se considerar a variabilidade entre as espécies, sua maturidade (idade da planta/teor de umidade), e variações nas estações do ano. Assim, esta técnica apresenta limitações devido à quantidade de calibrações necessárias para realizar a estimativa da massa de forragem, além de apresentar um custo oneroso para a obtenção do devido equipamento de avaliação.

- Estimativa atravavés de modelos matemáticos: De maneira geral, as avaliações indiretas baseiam-se em modelos matemáticos, onde se correlacionam os fatores que influenciam a produção de forragem e $o$ método de avaliação para encontrar uma equação que explique de maneira confiável o comportamento dos dados. No entanto, na maioria dos métodos indiretos é necessário que seja feita uma dupla amostram (uma direta, destrutiva, e uma através do método indireto escolhido), para que possa ser feita a calibração das curvas (Gomes et al., 2014). Neste sentido, a obtenção de estimativas através de modelos matemáticos gerados a partir de banco de dados e sua correlação com as variáveis ambientais é mais uma opção disponível como método de avaliação de massa de forragem (Silva Neto et al., 2015).

A modelagem matemática para a estimativa de forragem é um método com potencial crescimento de utilização, onde alguns modelos como o CROPGRO-PFM (Pequeno et al., 2018; Pequeno et al., 2014), APSIM (Araújo et al., 2013), ORCHIDEE (Chang et al., 2013) já estão sendo utilizados e aperfeiçoados 
para a estimativa de forragem de maneira prática e concisa. Apesar disto, ainda é necessário compreender as interações complexas entre espécie e ambiente para que a aplicação da modelagem matemática seja de fato eficiente, visto que é necessário agrupar toda fonte de variação envolvida no processo de acúmulo de massa.

- Uso de sensoriamento remoto: Salimon \& Anderson (2017) descreveram que esta é uma tecnologia que possui capacidade de avaliar grandes áreas em menor tempo, provocando o interesse, na última década, acerca desta metodologia. Segundo Pinguello et al. (2020) esta tecnologia é baseada na utilização de dados eletromagnéticos, onde geralmente é utilizado o Índice de Vegetação por Diferença Normalizada (NDVI) que leva em consideração as reflectâncias nos comprimentos de onda vermelho e infravermelho próximo. Ainda segundo os autores, quando existe maior produção e forragem, maior é a quantidade de luz visível absorvida, e do infravermelho próximo refletida, acontecendo o inverso quando a vegetação possui menor produção de massa forrageira. Hott et al. (2016) utilizaram o método de monitoramento remoto baseado no NDVI para avaliar o desenvolvimento de pastagens e relataram que os locais que apresentaram índices menores, poderiam estar relacionados à algum estágio de degradação. Neste sentido, Pereira et al. (2018) avaliaram a dinâmica de degradação de pastagens localizadas na Mata Atlântica de Minas Gerais, e relatam que a técnica de NDVI é eficiente em estimar a produção de forragem na região (Figura 10).

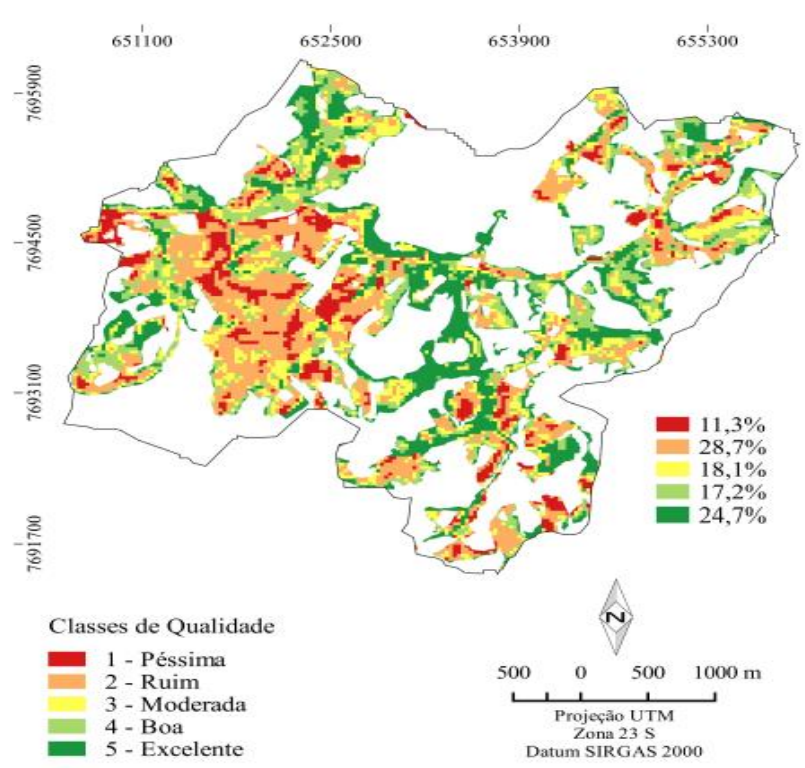

Figura 5. Qualidade das pastagens na bacia do córrego Dornelas. As classes de qualidade da pastagem baseado no seu nível de degradação são descritas como: 1- Nível extremo de degradação, com grandes manchas de solo exposto, com pouca ou nenhuma cobertura vegetal, geralmente acompanhada por erosões muito intensas. 2- Nível de degradação forte, com cobertura vegetal moderada com baixo vigor, associadas a erosões fortes, geralmente de forma laminar. 3- Nível de degradação moderado, com pequenas manchas de solo exposto, pode apresentar erosões em diferentes graus, mas sem a formação de grandes sulcos. 4- Nível de degradação leve, com raras manchas de solo exposto, boa cobertura vegetal e erosões em grau leve, no entanto raramente presentes. 5- Pastagem não degradada, com ausência de manchas expostas de solo, cobertura vegetal com alto vigor sem erosão aparente. Adaptado de Pereira et al. (2018).

É possível, então, que através do uso de sensoriamento remoto surjam técnicas de estratégias de tomadas de decisão para o gerenciamento de pastagens. Neste sentido, Pinguello et al. (2020) sugeriram que juntamente ao índice NDVI, sejam incrementadas avaliações remotas com o intuito de ajustar os modelos de predição de massa de forragem, resultando em maior precisão desses dados.

\section{Estimativas de consumo e pastejo por ruminantes}

O ambiente pastoril é composto por vários fatores que afetam a condição do dossel forrageiro, sendo formado por uma relação entre solo-planta-clima-animal. $\mathrm{O}$ ecossistema de pastagem é um ambiente 
heterogêneo e complexo, onde as plantas presentes no sistema possuem capacidade de adaptação fenológica em resta ao ambiente, incluindo a espécie de animal pastejadora (Carvalho et al., 2015). Desta maneira, Silva et al (2016) sugeriram que a experimentação com pastagens inclua o animal para que haja proximidade das condições reais de pastejo.

Neste sentido, o efeito do pisoteamento, padrão de desfolhação, hábito de pastejo e seletividade pelo animal estarão presentes durante as avaliações trazendo uma possibilidade de grande sucesso nas definições de estratégias de pastejo. Assim, respostas derivadas de um ambiente similar à realidade podem resultar em aumento na produtividade, resultando no incremento econômico da atividade agropecuária (Barros et al., 2010).

Segundo Berchielli et al. (2011) o consumo do animal é um dos componentes mais importantes na nutrição de ruminantes, visto que determinará o nível de nutrientes ingeridos e consequentemente seu desempenho. Fatores como diferenças na estrutura do dossel forrageiro pode resultar em alterações no hábito de pastejo do animal, afetando diretamente o consumo de forragem. Assim, é de fundamental importância que as pesquisas correlacionem o consumo do animal juntamente com a seletividade e composição química do alimento consumido (Vanzant et al., 2020). Neste sentido, as estimativas de consumo e seletividade do animal em pastejo pode ser realizado a partir dos seguintes métodos:

- Diferença de peso do animal e na massa de forragem: Baseia-se na estimativa de consumo animal pela diferença entre os pesos dos animais no pré e pós pastejo. Segundo Barros et al. (2010) é necessário que os animais utilizem uma bolsa coletora de fezes e urina para que não haja perda dessas excreções, visto que será necessário ser pesado junto com o animal, para estimar o consumo de forragem. Neste sentido, Allden \& McDWhittaker (1970) descreveram que a estimativa do consumo (C) pela diferença de peso animal pode ser conseguida pela seguinte equação:

\section{$\mathrm{C}=\frac{[(\text { peso pós pastejo }- \text { peso pré pastejo })+\text { perdas insensíveis de calor }]}{\text { Tempo de pastejo }(\min )}$}

Para estimativa das perdas insensíveis de calor utiliza-se uma espécie de focinheira que impede o animal de pastejar (Deminicis, 2015). Desta maneira, de acordo com Barros et al. (2010) o animal perde energia e peso, sem ingerir alimentos, estimando-se assim suas perdas metabólicas. Ainda segundo os autores, fraldas geriátricas podem ser utilizadas como bolsas coletoras fixadas ao animal (Figura 11), onde essas devem suportar a excreta de forma que não haja perdas subestimando o consumo do animal.

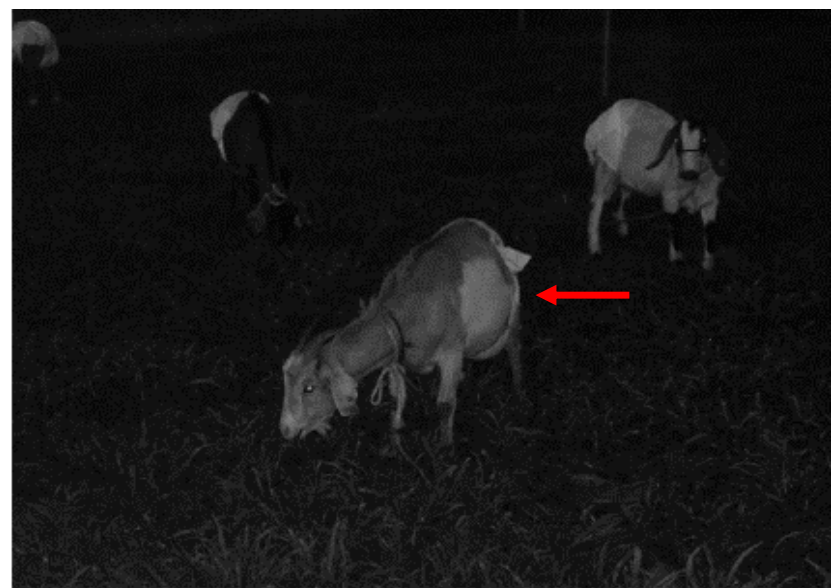

Figura 6. Caprinos em pastejo com fralda geriátrica para avaliação do consumo. É importante ressaltar que deve ser realizado um período de adaptação aos animais que receberão as bolsas coletoras, uma vez que a inclusão deste método pode afetar o hábito de pastejo do animal. Adicionalmente, é sugerido que esta técnica tenha capacidade de ser mais prática quando utilizada na experimentação de pequenos ruminantes, considerando o maior teor de matéria seca das fezes, bem como menor tamanho dos animais. Assim, é possível evitar perdas das excretas e evitar que o peso da fralda cause algum dano ao animal avaliado. No detalhe à direita, caprino com focinheira impedindo seu pastejo. Adaptado de Barros et al., (2010); Berchielli et al. (2011). 
De acordo com Barros et al. (2010) também é possível estimar o consumo (C) do animal pela diferença da massa de forragem, seguindo a fórmula:

$$
\mathrm{C}=\frac{\text { (Massa de forragem pré pastejo }- \text { Massa de forragem pós pastejo })}{\left(\mathrm{N}^{\mathbf{0}} \text { de animais * dias de pastejo }\right)}
$$

No entanto, ainda segundo os autores, para utilizar este método de estimativa é necessário que haja uma coleta de um grande número de amostras, para reduzir a possibilidade de erros, devido a variabilidade da forragem. Desta maneira, a utilização deste método ser uma alternativa eficaz quando avaliados em curtos períodos de tempo em dosséis homogêneos (Deminicis, 2015). Contudo, Berchielli et al. (2011) alertaram que em ambos os métodos de estimativa de consumo, existe limitações. Segundo os autores, ao estimar o consumo do animal através da diferença de peso, se leva em conta o material fresco consumido, não o material seco, visto que não se conhece a composição química da forragem ingerida. Ademais, ao estimar o consumo através da diferença entre a massa de forragem pode haver uma superestimava, visto que fatores como pisoteio podem reduzir a MF sem que ela tenha sido pastejada.

- Método do pastejo simulado: Consiste na observação do pastejo entre 15 a 30 minutos, seguidas pela coleta manual de uma amostra semelhante ao que o animal consumiu (Morais et al., 2018). Segundo Pedreira (2002) é necessário que haja treinamento prévio das pessoas que farão coleta, para que a simulação seja representativa diminuindo a possibilidade de erros. Adicionalmente, devido a variabilidade entre as pessoas que farão a coleta, é sugerido que esta técnica seja realizada quando existe uma grande quantidade de área de forragem disponível para avaliação, além da utilização de animais dóceis para facilitação do manejo.

- Cânula esofágica (extrusa): Devido ao hábito de pastejo seletivo, é comum a utilização de animais fistulados com o objetivo de avaliar o consumo. De acordo com Morais et al. (2018) o método consiste na colocação de uma cânula através de uma fistula, feita de forma cirúrgica no esôfago. Ainda segundo os autores os animais fistulados recebem jejum de 12 horas, seguido da alocação da bolsa coletora no momento que os animais vão ao pastejo. Após o pastejo, o material da extrusa (forragem contida na bolsa coletora) é retirado, sendo recolocado a cânula no animal. A amostra de extrusa então é seca em estufa de ventilação forçada a uma temperatura de $55^{\circ}$ durante $72 \mathrm{~h}$, moídas e analisadas para obtenção da sua composição química (Garcia et al., 2011).

Além disso, segundo Trindade et al. (2007) é possível avaliar a composição botânica do material presente nas bolsas coletoras através do seguimento dos passos a seguir: Após retirada da extrusa, o material é lavado para retirar o excesso de saliva, e facilitar a visualização dos componentes morfológicos ingeridos. Depois da lavagem e homogeneização da amostra, é retirada uma alíquota na qual é colocada sob uma bandeja de vidro, onde será selecionado o material e feita a coleta dos fragmentos para identificação da presença de folha, colmo e material morto na forragem consumida.

Tabela 9. Composição química de amostras de capim mombaça (Panicum maximum cv. Mombaça) obtidas através de extrusa e pastejo simulado.

\begin{tabular}{lcc}
\hline Variável $^{1}(\%)$ & \multicolumn{2}{c}{ Método de avaliação } \\
\cline { 2 - 3 } & Extrusa & Pastejo simulado \\
\hline MS & $14,41 \mathrm{~b}$ & $22,30 \mathrm{a}$ \\
PB & $11,31 \mathrm{a}$ & $11,30 \mathrm{a}$ \\
EE & $1,05 \mathrm{~b}$ & $2,15 \mathrm{a}$ \\
FDN & $69,35 \mathrm{a}$ & $67,18 \mathrm{a}$ \\
FDA & $35,51 \mathrm{a}$ & $34,21 \mathrm{a}$ \\
Ligina & $4,99 \mathrm{a}$ & $4,33 \mathrm{a}$ \\
DIVMS & $66,02 \mathrm{a}$ & $65,91 \mathrm{a}$ \\
\hline
\end{tabular}

${ }^{1}$ Em porcentagem da MS. MS: Matéria seca; PB: Proteína Bruta; FDN: Fibra em detergente neutro; FDA: Fibra em detergente ácido; DIVMS: Digestibilidade in vitro da matéria seca. Médias seguidas por letras iguais na linha não diferem entre si pelo teste de F $(\mathrm{P}>0,05)$. Adaptado de Lista et al. (2007).

Esta técnica possui como desvantagens a necessidade da realização de cirurgias para a fistulação, requerendo cuidados para que não haja complicações ao animal (Arruda et al., 2011; Jobim et al., 2007 Vanzant et al., 2020). Adicionalmente, a amostra de extrusa pode ser contaminada com a saliva do 
animal, além disso, durante a mastigação partículas muito pequenas podem passar pelo esôfago, sem ser coletada na amostra (Berchielli et al., 2011).

Lista et al. (2007) compararam as estimativas da amostragem qualitativa de pastagens tropicais obtidas através do pastejo simulado e da cânula esofágica de bovinos. Os autores relataram que apesar de existir diferenças ente os métodos, o pastejo simulado permite alcançar resultados semelhantes ao método da cânula esofágica (Tabela 9).

Cóser et al. (2008) compararam as estimativas de qualidade da forragem obtidas através do método de corte da planta e do pastejo simulado, e assim observaram diferença entre os métodos avaliados (Tabela 10). Desta maneira é possível observar que existe diferenças nas estimativas, de acordo com o método escolhido. Ademais, independentemente da escolha do método de avaliação é importante que a técnica seja realizada durante todo experimento, assim todos os tratamentos avaliados serão estimados a partir de uma técnica em comum.

Tabela 10. Teores $(\%)$ de proteína bruta (PB), fibra em detergente neutro (FDN) e digestibilidade in vitro da matéria seca (DIVMS) de amostras de capim elefante obtidas sob dois métodos.

\begin{tabular}{lcc}
\hline Variável $^{1}(\%)$ & \multicolumn{2}{c}{ Método de avaliação } \\
\cline { 2 - 3 } & Corte da planta & Pastejo simulado \\
\hline PB & $8,6 \mathrm{~b}$ & $12,8 \mathrm{a}$ \\
FDN & $65,5 \mathrm{a}$ & $66, \mathrm{a}$ \\
DIVMS & $59,9 \mathrm{~b}$ & $65,74 \mathrm{a}$ \\
\hline
\end{tabular}

${ }^{1}$ Em porcentagem da matéria seca. PB: Proteína Bruta; FDN: Fibra em detergente neutro; DIVMS: Digestibilidade in vitro da matéria seca. Médias seguidas por letras iguais na linha não diferem entre si pelo teste de F (P>0,05). Fonte: Adaptado de Cóser et al. (2008).

De maneira semelhante, Pereira et al. (2014) avaliaram três métodos para estimar as características qualitativas de clones de capim elefante anão (BRS Kurumi e CNPGL 0013): avaliação da planta inteira através de corte (15 cm de resíduo), método da extrusa e o método de pastejo simulado. Os autores relataram que a técnica de pastejo simulado é uma estimativa que se aproxima ao método da extrusa, podendo ser utilizado desde que as pessoas que coletem a amostra sejam treinadas. Adicionalmente, os autores sugerem a técnica de amostragem da planta inteira não representa a dieta selecionada pelo animal (Tabela 11). Isto acontece, pois, ao considerar que o consumo do animal seja representado pelo corte da planta em determinada altura de resíduo, não está incluso o hábito de seleção de pastejo do animal, podendo resultar em sub ou superestimativas de consumo.

Tabela 11. Composição química de amostras de clones de capim elefante anão (BRS Kurumi e CNPGL 0013) obtidas através de diferentes métodos de amostragem.

\begin{tabular}{lcccc}
\hline \multirow{2}{*}{ Variável (\%) } & \multicolumn{3}{c}{ Método avaliado } & \multirow{2}{*}{ CV (\%) } \\
\cline { 2 - 4 } & Planta inteira & Extrusa & Pastejo simulado & 20 \\
\hline PB & $9,6 \mathrm{~b}$ & $13,3 \mathrm{a}$ & $13,6 \mathrm{a}$ & 9,1 \\
FDN & $64,2 \mathrm{~b}$ & $68,9 \mathrm{a}$ & $61 \mathrm{c}$ & 5,6 \\
FDA & $33,4 \mathrm{~b}$ & $34,9 \mathrm{a}$ & $32,4 \mathrm{c}$ & 8,9 \\
Celulose & $30,4 \mathrm{~b}$ & $31,7 \mathrm{a}$ & $30 \mathrm{~b}$ & 16,6 \\
Lignina & $2,9 \mathrm{~b}$ & $3,5 \mathrm{a}$ & $2,9 \mathrm{~b}$ & 3,7 \\
DIVMS & $66,1 \mathrm{c}$ & $71,3 \mathrm{a}$ & $74,2 \mathrm{a}$ & 3 \\
\hline
\end{tabular}

PB: Proteína Bruta; FDN: Fibra em detergente neutro; FDA: Fibra em detergente ácido; DIVMS: Digestibilidade in vitro da matéria seca; CV: Coeficiente de Variação. Médias seguidas por letras iguais na linha não diferem entre si pelo teste de Tukey $(\mathrm{P}>0,05)$. Adaptado de Pereira et al. $(\underline{2014})$

\section{Considerações Finais}

A experimentação com plantas forrageiras é de fundamental importância para conhecimento de suas características quantitativas e qualitativas. Para tanto, durante a experimentação é necessário integrar as ações climáticas, e se possível, o animal, para simular o ambiente real de pastejo, e suas variações sazonais. Assim, por ser um ambiente complexo, com várias interações entre os fatores presentes no ecossistema, a escolha do método de avaliação deve ser feita objetivando alcançar resultados precisos, com alta confiabilidade. 
A quantificação da produção de massa forrageira é uma característica fundamental para a elaboração de estratégias de pastejo, testadas previamente em forma de experimentos. Além disso, o entendimento acerca das características qualitativas da forragem consumida pelo animal deve ser incluído dentro da experimentação para obter a relação entre produção de massa e composição nutricional do alimento. Assim, é possível obter uma estimativa de uma estratégia de manejo que atende as necessidades do animal em equilíbrio com a produtividade do dossel forrageiro.

Métodos diretos e indiretos para estimar a quantificação de forragem são comumente utilizados na experimentação vegetal com ou sem animais. Neste sentido, não existe um método mais correto que outro, mas sim, métodos mais precisos em comparação à outras técnicas para estimar a mesma variável. Desta maneira a escolha do método de avaliação utilizado irá depender da fonte e limitação de recursos necessários para realizar determinada pesquisa. Assim, independentemente do método utilizado para estimar a variável desejada, este deve ser utilizado durante todo o experimento para que as fontes de variação sejam analisadas sob a mesma técnica.

\section{Referências bibliográficas}

Allden, W. G., \& McDWhittaker, I. A. (1970). The determinants of herbage intake by grazing sheep: the interrelationship of factors influencing herbage intake and availability. Australian Journal of Agricultural Research, 21(5), 755-766.

Araújo, L. C., Santos, P. M., Rodriguez, D., Pezzopane, J. R. M., Oliveira, P. P. A., \& Cruz, P. G. (2013). Simulating Guinea grass production: empirical and mechanistic approaches. Agronomy Journal, 105(1), 61-69. https://doi.org/10.2134/agronj2012.0245.

Arruda, D. S. R., Canto, M. W. do, Jobim, C. C., \& Carvalho, P. C. F. (2011). Métodos de avaliação de massa de forragem em pastagens de capim-estrela submetidas a intensidades de pastejo. Ciência Rural, 41, 2004-2009. https://doi.org/10.1590/S0103-84782011005000141.

Barros, C. S., Dittrich, J. R., Monteiro, A. L. G., Pinto, S., \& Warpechowski, M. B. (2010). Técnicas para estudos de consumo de alimentos por ruminantes em pastejo: revisão. Scientia Agraria Paranaensis, 9(2), 5-24. https://doi.org/10.18188/sap.v9i2.4569.

Berchielli, T. T., Pires, A. V, Oliveira, S. G., \& FUNEP. (2011). Nutrição de Ruminantes (Issue 2th ed.). FUNEP.

Bonnet, O. J. F., Meuret, M., Tischler, M. R., Cezimbra, I. M., Azambuja, J. C. R., \& Carvalho, P. C. F. (2015). Continuous bite monitoring: a method to assess the foraging dynamics of herbivores in natural grazing conditions. Animal Production Science, 55(3), 339-349. https://doi.org/10.1071/AN14540.

Braga, G. J., Pedreira, C. G. S., Herling, V. R., Luz, P. H. de C., Marchesin, W. A., \& Macedo, F. B. (2009). Quantifying herbage mass on rotationally stocked palisadegrass pastures using indirect methods. Scientia Agricola, 66, 127-131. https://doi.org/10.1590/S0103-90162009000100018.

Carvalho, P. C. F., Bremm, C., Mezzalira, J. C., Fonseca, L., Trindade, J. K., Bonnet, O. J. F., Tischler, M., Genro, T. C. M., Nabinger, C., \& Laca, E. A. (2015). Can animal performance be predicted from short-term grazing processes? Animal Production Science, 55(3), 319-327. https://doi.org/10.1071/AN14546.

Carvalho, R. (2008). Método de determinação da disponibilidade de forragem. Ciência et Praxis, 1(2), 7-10.

Carvalho, W. T. V., Minighin, D. C., Gonçalves, L. C., Villanova, D. F. Q., Mauricio, R. M., \& Pereira, R. V. G. (2017). Pastagens degradadas e técnicas de recuperação: Revisão. PUBVET, 11, 947-1073. https://doi.org/10.22256/PUBVET.V11N10.1036-1045.

Chang, J. F., Viovy, N., Vuichard, N., Ciais, P., Wang, T., Cozic, A., Lardy, R., Graux, A.-I., Klumpp, K., \& Martin, R. (2013). Incorporating grassland management in ORCHIDEE: model description and evaluation at 11 eddy-covariance sites in Europe. Geoscientific Model Development, 6(6), 21652181. https://doi.org/10.5194/gmd-6-2165-2013.

Cóser, A. C., Martins, C. E., Deresz, F., Freitas, A. F., Paciullo, D. S. C., Alencar, C. A. B., \& Vítor, C. M. T. (2008). Produção de forragem e valor nutritivo do capim-elefante, irrigado durante a época 
seca. Pesquisa Agropecuária Brasileira, 43, 1625-1631. https://doi.org/10.1590/S0100$204 X 2008001100023$.

Cóser, A. C., Martins, C. E., Deresz, F., Freitas, A. F., Paciullo, D. S. C., Salvati, J. A., \& Schimidt, L. T. (2003). Métodos para estimar a forragem consumível em pastagem de capim-elefante. Pesquisa Agropecuária Brasileira, 38(7), 875-879. https://doi.org/10.1590/S0100-204X2003000700012.

Deminicis, B. B. (2015). Novas tecnologias aplicadas na avaliação da produção e qualidade de forragens. Ciências Agrárias, 1, 247-256. https://doi.org/10.12702/978-85-68205-03-7.14.

Dufloth, J. H., Back, Á. J., \& Passos, R. (2015). Estimativa da produção de pasto através de dois métodos indiretos: Régua (altura) e Disco Medidor (densidade). Agropecuária Catarinense, 28(1), 83-86.

Edvan, R. L, Bezerra, L. R., Marques, C. A. T., Carneiro, M. S. S., Oliveira, R. L., \& Ferreira, R. R. (2016). Methods for estimating forage mass in pastures in a tropical climate. Revista de Ciências Agrárias, 39(1), 36-45. https://doi.org/10.19084/RCA14100.

Edvan, R. L., Fernades, P. D., Carneiro, M. S. S., Neder, D. G., Araujo, J. S., Andrade, A. P., \& Souto Filho, L. T. (2013). Acúmulo de biomassa e crescimento radicular da palma forrageira em diferentes épocas de colheita. Revista Acadêmica Ciência Animal, 11(4), 373-381.

Fontes, P. T. N., Sousa, B. M. de L., Oliveira, L. F. G. de, Fagundes, J. L., Backes, A. A., Nascimento, G. A., Florêncio, R. S. R., \& Santos, A. L. H. (2020). Population dynamics and structural characteristics of'Survenola'digit grass subjected to intermittent defoliation strategies. Pesquisa Agropecuária Brasileira, 55, 1-10. https://doi.org/10.1590/s1678-3921.pab2020.v55.01602.

Garcia, C. de S., Fernandes, A. M., Fontes, C. A. A., Vieira, R. A. M., Sant'Ana, N. F., \& Pimentel, V. A. (2011). Desempenho de novilhos mantidos em pastagens de capim-elefante e capim-mombaça. Revista Brasileira de Zootecnia, 40, 403-410. https://doi.org/10.1590/S1516-35982011000200023.

Gomes, L. L., Cóser, A. C., Oliveira, A. P. G., Stradiotti Júnior, D., Almeida, F. M., Marcelino, L. L., \& Morenz, M. J. F. (2014). Métodos de amostragem quantitativa direta e indireta de plantas forrageiras e pastagens. In B. B. Deminicis \& C. B. Martins (Eds.), Tópicos Especiais em Ciência Animal III (p. 39).

Gomide, J. A., Wendling, I. J., Bras, S. P., \& Quadros, H. B. (2001). Consumo e produção de leite de vacas mestiças em pastagem de Brachiaria decumbens manejada sob duas ofertas diárias de forragem. Revista Brasileira de Zootecnia, 30, 1194-1199. https://doi.org/10.1590/S151635982001000500009.

Hodgson, J. (1981). Variations in the surface characteristics of the sward and the short-term rate of herbage intake by calves and lambs. Grass and Forage Science, 36(1), 49-57. https://doi.org/10.1111/j.1365-2494.1981.tb01538.x

Hodgson, J. (1990). Grazing management. Science into practice. Longman Group UK Ltd.

Hott, M. C., Carvalho, L. M. T., Antunes, M. A. H., Santos, P. A., Arantes, T. B., Resende, J. C. de, \& Rocha, W. S. D. (2016). Vegetative growth of grasslands based on hyper-temporal NDVI data from the Modis sensor. Pesquisa Agropecuária Brasileira, 51, 858-868. https://doi.org/10.1590/S0100-204X2016000700009.

Huuskonen, A., Huhtanen, P., \& Joki-Tokola, E. (2013). The development of a model to predict feed intake by growing cattle. Livestock Science, 158(1-3), 74-83. https://doi.org/http://dx.doi.org/10.1016/j.livsci.2013.10.005

Jobim, C. C., Nussio, L. G., Reis, R. A., \& Schmidt, P. (2007). Avanços metodológicos na avaliação da qualidade da forragem conservada. Revista Brasileira de Zootecnia, 36(Especial), 101-119. https://doi.org/http://dx.doi.org/10.1590/S1516-35982007001000013.

Lima, S. F., Timossi, P. C., \& Assunção, H. F. (2015). Análise comparativa de técnicas de estimativa de fração de cobertura vegetal por Urochloa ruziziensis e Urochloa spp. Planta Daninha, 33, 483490. https://doi.org/10.1590/S0100-83582015000300010.

Lista, F. N., Silva, J. F. C., Vásquez, H. M., Detmann, E., Domingues, F. N., \& Ferolla, F. S. (2007). Avaliação de métodos de amostragem qualitativa em pastagens tropicais manejadas em sistema rotacionado. Revista Brasileira de Zootecnia, 36, 1413-1418. https://doi.org/10.1590/S1516-35982007000600026.

Maciel, M. S., Santana Júnior, H. A., Cardoso, E. O., Oliveira, Elves Souza CardosoSantos, M. S., \& Filho, G. A. (2014). Avaliação de pastagem com animais: do tradicional ao moderno. Nutrime, 11(5), 3700-3713. 
Martins, C. D. M., Schmitt, D., Duchini, P. G., Miqueloto, T., \& Sbrissia, A. F. (2020). Defoliation intensity and leaf area index recovery in defoliated swards: implications for forage accumulation. Scientia Agricola, 78(2), 1-10. https://doi.org/10.1590/1678-992x-2019-0095.

Morais, L. F., Carvalho, C. A. B., Anjos, A. N. A., Viegas, C. R., \& Silva, P. H. F. (2018). Avanços na avaliação de pastagens cultivadas com forrageiras tropicais no Brasil: Uma Revisão. Revista Brasileira de Tecnologia Aplicada Nas Ciências Agrárias, 11(2), 125-136. https://doi.org/10.5935/PAeT.V11.N2.13.

Moterle, P. H., Rocha, M. G., Pötter, L., Sichonany, M. J. O., Amaral, L. G. A., Silva, M. F., Salvador, P. R., \& Vicente, J. M. (2017). Padrões de deslocamento de bezerras de corte recebendo suplemento em pastagem de azevém. Arquivo Brasileiro de Medicina Veterinária e Zootecnia, 69, 1021-1029. https://doi.org/10.1590/1678-4162-9258.

Paciullo, D. S. C., Aroeira, L. J. M., Cóser, A. C., \& Cardoso, R. C. (2004). Uso do método do disco e da altura da planta para estimar a massa de forragem em relvado de Cynodon spp. Ciência Rural, 34(2), 599-601. https://doi.org/10.1590/S0103-84782004000200044.

Pedreira, C. G. S. (2002). Avanços metodológicos na avaliação de pastagens. Reunião Anual Da SWociedade Brasileira de Zootecnia, 100-150.

Pellegrini, C. B., Moojen, E. L., Silva, J. H. S., Rocha, M. G., Brum, M. S., \& Gravina, F. S. (2010). Precisão da estimativa da massa de forragem com discos medidores em pastagem nativa. Ciência Rural, 40, 163-169. https://doi.org/10.1590/S0103-84782010000100026.

Pequeno, D N L, Pedreira, C. G. S., Boote, K. J., Alderman, P. D., \& Faria, A. F. G. (2018). Speciesgenotypic parameters of the CROPGRO Perennial Forage Model: Implications for comparison of three tropical pasture grasses. Grass and Forage Science, 73(2), 440-455. https://doi.org/10.1111/gfs.12329.

Pequeno, Diego N L, Pedreira, C. G. S., \& Boote, K. J. (2014). Simulating forage production of Marandu palisade grass (Brachiaria brizantha) with the CROPGRO-Perennial Forage model. Crop and Pasture Science, 65(12), 1335-1348. https://doi.org/10.1071/CP14058.

Pereira, L. F., Ferreira, C. F. C., \& Guimarães, R. M. F. (2018). Manejo, qualidade e dinâmica da degradação de pastagens na Mata Atlântica de Minas Gerais-Brasil. Nativa, Sinop, 6(4), 370-379. https://doi.org/10.31413/nativa.v6i4.5542.

Pereira, T. P., Modesto, E. C., Campana, L. L., Gomide, C. A. M., Paciullo, D. S. C., Nepomuceno, D. D., Carvalho, C. A. B., Morenz, M. J. F., \& Almeida, J. C. C. (2014). Caracterização da forragem e da extrusa de clones de capim elefante anão sob lotação intermitente. Semina Ciencias Agrárias, 35(5), 2635-2648. https://doi.org/10.5433/1679-0359.2014v35n5p2635.

Pimentel, R. M., Bayão, G. F. V., Lelis, D. L., Cardoso, A. J. S., Saldarriaga, F. V., Melo, C. C. V., Souza, F. B. M., \& Santos, M. E. R. (2016). Ecofisiologia de plantas forrageiras. PUBVET, 10, 636720. https://doi.org/10.22256/pubvet.v10n9.666-679..

Pinguello, A. J. C., Tameirão, E. R., Gonzaga, L. W. F., Mongelli, M. S., Faria, P. H. A., Ferrante, M., \& Fernández, F. E. (2020). Uso de índice de vegetação da diferença normalizada na estimativa de produção de forragem. PUBVET, 14(3), 1-7. https://doi.org/10.31533/pubvet.v14n3a538.1-7.

Salimon, C., \& Anderson, L. (2018). How strong is the relationship between rainfall variability and Caatinga productivity? A case study under a changing climate. Anais Da Academia Brasileira de Ciências, 90, 2121-2127. https://doi.org/10.1590/0001-3765201720170143.

Salman, A. K. D., Soares, J. P. G., \& Canesin, R. C. (2006). Métodos de amostragem para avaliação quantitativa de pastagens. Embrapa Rondônia-Circular Técnica, 84.

Sbrissia, A. F., Duchini, P. G., Zanini, G. D., Santos, G. T., Padilha, D. A., \& Schmitt, D. (2018). Defoliation strategies in pastures submitted to intermittent stocking method: underlying mechanisms buffering forage accumulation over a range of grazing heights. Crop Science, 58(2), 945-954. https://doi.org/10.2135/cropsci2017.07.0447.

Silva, D. J., \& Queiroz, A. C. (2002). Análise de alimentos: métodos químicos e biológicos (3rd ed.). Universdiade Federal de Viçosa.

Silva, G. M., Silva, F. F., Viana, P. T., Rodrigues, E. S. O., Moreira, C. N., de Almeida Meneses, M., 
Abreu Júnior, J. S., Rufino, C. A., \& Barreto, L. S. (2016). Avaliação de forrageiras tropicais: revisão. PUBVET, 10, 190-270.

Silva Neto, S. P., Santos, A. C., Garcia, R. N., Dias, J. L. A., Silva, Á. M., \& Pereira, P. A. R. (2015). Variabilidade espacial da biomassa da forragem e taxa de lotação animal em pastagem de capim Marandu. Revista Agrogeoambiental, 8(2), 119-130. https://doi.org/10.18406/2316-1817v8n22016856.

Silva, P. H. F., Anjos, A. N. A., Viegas, C. R., Morais, L. F., Nepomuceno, D. D., \& Carvalho, C. L. F. (2018). Procedimentos para estimar massa de forragem, interceptação luminosa e índice de área foliar em pastos de capim-Tanzânia. Archivos de Zootecnia, 67(259), 404-407. https://doi.org/http://dx.doi.org/10.21071/az.v67i259.3797.

Silva, S C, Bueno, A. A. O., Carnevalli, R. A., Silva, G. P., \& Chiavegato, M. B. (2019). Nutritive value and morphological characteristics of Mombaça grass managed with different rotational grazing strategies. The Journal of Agricultural Science, 157(7-8), 592-598. https://doi.org/10.1017/S0021859620000052.

Silva, Sila Carneiro, \& Cunha, W. F. (2003). Métodos indiretos para estimar a massa de forragem em pastos de Cynodon spp. Pesquisa Agropecuária Brasileira, 38, 981-989. https://doi.org//10.1590/S0100-204X2003000800011.

Silva, Sila Carneiro, Sbrissia, A. F., \& Pereira, L. E. T. (2015). Ecophysiology of C 4 forage grassesunderstanding plant growth for optimising their use and management. Agriculture, 5(3), 1-28. https://doi.org/10.3390/agriculture5030598.

Suyama, H., Benes, S. E., Robinson, P. H., Getachew, G., Grattan, S. R., \& Grieve, C. M. (2007). Biomass yield and nutritional quality of forage species under long-term irrigation with saline-sodic drainage water: Field evaluation. Animal Feed Science and Technology, 135(3-4), 329-345. https://doi.org/http://dx.doi.org/10.1016/j.anifeedsci.2006.08.010

Trindade, J. K., Silva, S. C., Souza Júnior, S. J., Giacomini, A. A., Zeferino, C. V, Guarda, V. A., \& Carvalho, P. C. F. (2007). Composição morfológica da forragem consumida por bovinos de corte durante o rebaixamento do capim-marandu submetido a estratégias de pastejo rotativo. Pesquisa Agropecuária Brasileira, 42(6), 883-890.

Vanzant E. S., Cochran, R. C. \& Coblentz, W. K. (2020). Animals Methods for Evaluating Forage Quality. In: Moore, K. J.; Collins, M.; Nelson, C. J.; Redfearn, D. D. (Eds.). Forage: The Science Of Grassland Agriculture. Croydon: Willey Blackwell, 37, 673-685.

Yokoyama, L. P., Viana Filho, A., Balbino, L. C., Oliveira, I. P. de, \& Barcellos, A. de O. (1999). Avaliação econômica de técnicas de recuperação de pastagens. Pesquisa Agropecuária Brasileira, 34(8), 1335-1345.

Zanine, A. M., Santos, E. M., \& Ferreira, D. J. (2006). Principales métodos de evaluación de pasturas. Revista Electrónica de Veterinaria, 7(11), 1-13.

Histórico do artigo:

Recebido: 22 de julho de 2021

Aprovado: 2 de setembro de 2021

Disponível online: 23 de novembro de 2021
Licenciamento: Este artigo é publicado na modalidade Acesso Aberto sob a licença Creative Commons Atribuição 4.0 (CC-BY 4.0), a qual permite uso irrestrito, distribuição, reprodução em qualquer meio, desde que o autor e a fonte sejam devidamente creditados. 